\title{
Distinct functions of junD in cardiac hypertrophy and heart failure
}

\author{
Romeo Ricci, ${ }^{1,2}$ Urs Eriksson,,${ }^{3,4,10}$ \\ Gavin Y. Oudit, ${ }^{5,10}$ Robert Eferl, ${ }^{1,10}$ \\ Alexander Akhmedov, ${ }^{7,10}$ Izabela Sumara, ${ }^{8,10}$ \\ Grzegorz Sumara, ${ }^{1,2}$ Zamaneh Kassiri, ${ }^{6}$ \\ Jean-Pierre David, ${ }_{1}^{1}$ Latifa Bakiri, ${ }^{1}$ Bernd Sasse, \\ Maria-Helena Idarraga, ${ }^{1}$ Martina Rath ${ }^{1}$ \\ David Kurz, ${ }^{7}$ Hans-Christian Theussl, ${ }^{1}$ \\ Jean-Claude Perriard, ${ }^{2}$ Peter Backx ${ }^{5}$ \\ Josef M. Penninger, ${ }^{3}$ and Erwin F. Wagner ${ }^{1,11}$ \\ ${ }^{1}$ Institute of Molecular Pathology (IMP), A-1030 Vienna, \\ Austria; ${ }^{2}$ ETH Zurich, Institute of Cell Biology, CH-8093 \\ Zurich, Switzerland; ${ }^{3}$ IMBA Institute of Molecular \\ Biotechnology of the Austrian Academy of Sciences, A-1030 \\ Vienna, Austria; ${ }^{4}$ Experimental Critical Care Medicine, \\ Departments of Research and Internal Medicine, University \\ Hospital, CH-4031 Basel, Switzerland; ${ }^{5}$ Departments of \\ Physiology and Medicine and the University Health Network \\ Richard Lewar/Heart and Stroke Centre of Excellence, and \\ ${ }^{6}$ Ontario Cancer Institute, University of Toronto, Toronto \\ M5S 1A8, Canada; ${ }^{7}$ Institute of Physiology, Cardiovascular \\ Research and University Hospital of Zurich, Division of \\ Cardiology, CH-8091 Zurich, Switzerland; ${ }^{8}$ ETH Zurich, \\ Institute of Biochemistry, CH-8093 Zurich, Switzerland; \\ ${ }^{9}$ University Hospital of Zurich, Department of Pathology, \\ CH-8091 Zurich, Switzerland
}

Cardiac hypertrophic stimuli induce both adaptive and maladaptive growth response pathways in heart. Here we show that mice lacking junD develop less adaptive hypertrophy in heart after mechanical pressure overload, while cardiomyocyte-specific expression of junD in mice results in spontaneous ventricular dilation and decreased contractility. In contrast, fra-1 conditional knock-out mice have a normal hypertrophic response, whereas hearts from fra-1 transgenic mice decompensate prematurely. Moreover, fra-1 transgenic mice simultaneously lacking junD reveal a spontaneous dilated cardiomyopathy associated with increased cardiomyocyte apoptosis and a primary mitochondrial defect. These data suggest that junD promotes both adaptive-protective and maladaptive hypertrophy in heart, depending on its expression levels.

Supplemental material is available at http://www.genesdev.org.

Received April 27, 2004; revised version accepted November $15,2004$.

[Keywords: Cardiac hypertrophy; fra-1; junD; AP-1; heart failure; mitochondria]

${ }^{10}$ These authors contributed equally to the work.

${ }^{11}$ Corresponding author.

E-MAIL wagner@imp.univie.ac.at; FAX 43-1-7989370.

Article and publication are at http://www.genesdev.org/cgi/doi/10.1101/ gad.327005.
Hemodynamic overload initially results in an adaptive concentric hypertrophy in the heart, normalizing wall tension. Sustained pressure overload will override these adaptive mechanisms, leading to eccentric hypertrophy, decreased contractile function, and the development of heart failure (Chien 1999). Molecular pathways involved in cardiac hypertrophy can be specifically studied in vivo by exposing mice to either biomechanical stress through transaortic constriction of the aorta (TAC) (Rockman et al. 1991) or hormonally induced hypertrophy (Brancaccio et al. 2003; Oudit et al. 2003). This approach led to the identification of many signal transduction pathways involved in these processes (Frey and Olson 2003; Olson and Schneider 2003). Importantly, cardiomyocyte hypertrophy represents a typical feature of various primary cardiomyopathies (Hunter and Chien 1999), whereby diseased hearts frequently show cytoskeletal and extracellular matrix defects (Chien 2000) as well as mitochondrial DNA mutations and mitochondrial alterations (Wallace 1999).

The activator protein-1 (AP-1) transcription factors, consisting of dimeric complexes composed of the Jun, Fos, and ATF families, have specific functions in different organs, in particular following various stress stimuli (Jochum et al. 2001). Early up-regulation of the AP-1 transcription factors $c$-jun, $c$-fos, and junB has been described after cardiac hypertrophic stimuli (Parker and Schneider 1991). The AP-1 member junD, although dispensable in development (Thepot et al. 2000), has been shown to be involved in muscle cell differentiation (Andreucci et al. 2002). Interestingly, junD is specifically expressed in the developing heart and cardiovascular system (Thepot et al. 2000). Reduced junD expression has also been reported in human failing hearts (Pollack et al. 1997). Mice overexpressing the AP-1 member fos-related antigen-1 (fra-1) develop osteosclerosis (Jochum et al. 2000). There are conflicting data regarding fra-1 expression upon cardiac hypertrophic stimuli. One study demonstrated that fra-1 is not induced upon aortic banding (Rockman et al. 1991), whereas another study reported both repression and induction of fra- 1 expression in cardiomyocytes in vitro, depending on the stimulation (van Wamel et al. 2000). Interestingly, it has been reported that fra-1 seems to regulate the cardiac hypertrophy gene ANF (Kovacic-Milivojevic and Gardner 1995). However, the in vivo role of junD and fra-1 in heart physiology remains unknown.

\section{Results and Discussion}

JunD is essential for concentric cardiac hypertrophy upon mechanical pressure overload

We initially examined the expression of the different AP-1 members in the heart after mechanical pressure overload induced by TAC in wild-type mice using RNase protection assay (RPA). Consistent with previous studies (Rockman et al. 1991), we observed an early immediate up-regulation of $c$-jun, junB, and $c$-fos $1 \mathrm{~h}$ post-TAC followed by down-regulation $4 \mathrm{~h}$ after TAC. Likewise, fra-2 was strongly induced after banding and was decreased after $4 \mathrm{~h}$. Basal levels of fra-1 and $f \circ B$ were very low and only a minor induction of these two genes could be observed (Fig. 1A). JunD was only slightly induced after 
A
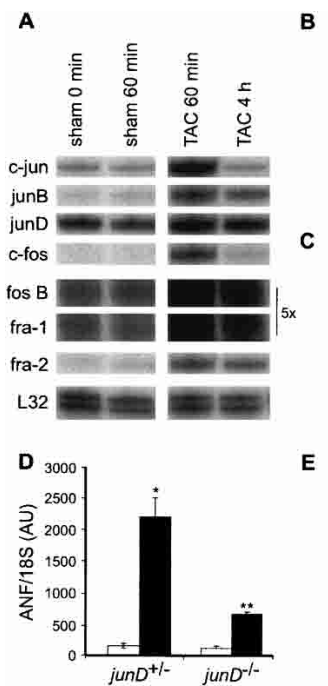

E
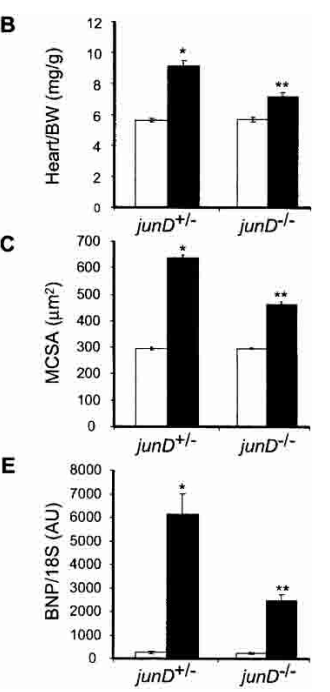

Figure 1. JunD is required for mechanically induced cardiac hypertrophy. (A) Expression of different AP-1 members and loading control (L32, indicated on the left) after aortic banding of wild-type mice. RNase protection assay showed marked early immediate upregulation of $c$-jun, junB, $c$-fos, and fra-2. JunD was expressed at high steady-state levels already in native hearts and was slightly increased after banding. Although fra-1 as well as FosB expression was low, a slight induction after aortic banding is visible on a five times higher exposure. $(B, C)$ Heart-to-body weight ratios $(B)$ and myocyte cross-sectional areas (MCSA) $(C)$ in jun $D^{-/-}$and jun $D^{+/}$ control mice 3 wk after severe TAC (black bars) and 3 wk after sham operation (open bars). $(D, E)$ Relative transcriptional expression of atrial natriuretic factor (ANF) $(D)$ and brain natriuretic peptide (BNP) $(E)$ in banded (black bars) and sham-operated (open bars) junD $D^{-/-}$and junD $D^{+/-}$control mice obtained by real-time RT-PCR. (AU) Arbitrary units. Hypertrophic response in junD $D^{-/}$mice was reduced compared with control mice $(n=9$, five males and four females, 4 mo old for TAC and $n=7$, four males and three females, 4 mo old for sham operation for both genotypes). $\left(^{\star}\right) p<0.01 \mathrm{com}-$ pared with all other groups (ANOVA with post hoc student Neuman Keuls multiple comparison test); $\left(^{\star \star}\right) p<0.05$ compared with respective sham group (student unpaired $t$-test).

TAC, but was expressed at high steady-state levels in hearts without stimulation.

Next, we asked for the role of junD in cardiac hypertrophy in response to chronic pressure overload and $\beta$-adrenergic stimulation by isoproterenol. We subjected jun $D^{-/-}$and control mice to severe and mild TAC. Although a significant increase of heart-to-body weight ratios in junD $D^{-/-}$mice was observed after severe TAC compared with sham-operated knock-out mice $(p<0.05)$, the same stimulus led to significantly more hypertrophy in jun $D^{+/-}$control mice $(p<0.01)$ (Fig. 1B). Consistently, myocyte cross-sectional areas were smaller compared with jun $D^{+/-}$mice after TAC $(p<0.01)$ (Fig. 1C). Upregulation of natriuretic peptides characterizes many forms of cardiac hypertrophy (Chien et al. 1993). Decreased hypertrophic response in jun $D^{-1-}$ mice was associated with decreased expression of atrial natriuretic factor (ANF) and brain natriuretic peptide (BNP) after TAC $(p<0.01)$ (Fig. 1D,E).

After mild TAC, hypertrophy assessed by measuring heart-to-body weight ratios in jun $D^{-/-}$hearts was almost absent (Supplementary Fig. S1A). Despite the absence of adaptive myocardial hypertrophy in these mice, junD ${ }^{-/-}$ hearts displayed normal echocardiographical parameters for cardiac function and contractility, since fractional

shortening (FS), velocity of circumferential shortening corrected for heart rate $\left(\mathrm{VCF}_{\mathrm{C}}\right)$, and peak aortic velocity corrected for heart rate $\left(\mathrm{PAV}_{\mathrm{C}}\right)$ were not reduced (Supplementary Fig. S1B-D) at least $6 \mathrm{wk}$ after mild TAC. To test whether these findings were specific for pressure overload-induced hypertrophy, we exposed junD $D^{-/-}$mice to $\beta$-adrenergic stimulation using isoproterenol infusions at a dosage that does not increase blood pressure. Isoproterenol was administered over a $14-d$ period. However, the absence of junD did not attenuate cardiac hypertrophy in response to isoproterenol (Supplementary Fig. S1E).

\section{JunD promotes ventricular dilation when overexpressed specifically in cardiomyocytes}

We next asked whether junD-dependent regulation of hypertrophy is cardiomyocyte specific. For this purpose, we first transfected cultured primary rat cardiomyocytes with a junD expression vector. Indeed, overexpression of junD in these cells led to a marked hypertrophic response compared with nontransfected cardiomyocytes (Supplementary Fig. S2). We then generated transgenic mice that express junD under the control of the cardiomyocyte-specific $\alpha$-MHC promoter $\left(\alpha-\right.$ MHC-jund ${ }^{\text {tg }}$ mice). Southern blot analysis confirmed stable integration of the transgene (Supplementary Fig. S3). Heart-specific expression of junD was tested by Western blotting (Fig. 2A). Echocardiography in 8-wk-old $\alpha$-MHC-jun ${ }^{\text {tg }}$ mice showed no significant alteration in anterior and posterior wall thickness (data not shown) as well as in left ventricular mass compared with wild-type controls (Fig. 2B). However, we found decreased heart contractility since FS was reduced in $\alpha-\mathrm{MHC}-j u n D^{\mathrm{tg}}$ mice $(p<0.02)$ (Fig. 2C). Decreased contractility was associated with ventricular dilation since hearts displayed increased left ventricular end systolic (LVESD) (Fig. 2D) and left ventricular end diastolic (LVEDD) diameters (Fig. 2E) $(p<0.01)$.

Fra-1 overexpression causes premature heart failure
upon pressure overload and $\beta$-adrenergic stimulation

In order to investigate the function of fra-1 in cardiac hypertrophy, we subjected fra-1 conditional knock-out mice (fra- $1^{\Delta / \Delta}$ mice) and fra-1 transgenic mice $\left(\right.$ fra- $1^{\mathrm{tg}}$ mice) to mild TAC. TAC resulted in a comparable hypertrophic response between both $\mathrm{fra}-1^{\Delta / \Delta}$ mice and wild-type mice, since heart-to-body weight ratios were similar (Supplementary Fig. S4A). Contractility assessed by echocardiography was preserved $6 \mathrm{wk}$ after surgery in both groups (Supplementary Fig. S4B-D).

In contrast, although heart-to-body weight ratios were similarly increased (Fig. 3A), cardiac contractility was reduced in $\mathrm{Fra}^{\mathrm{tg}}$ mice compared with wild-type mice

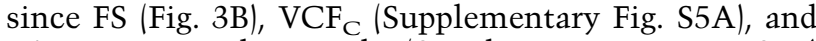
$\mathrm{PAV}_{\mathrm{C}}$ were decreased (Supplementary Fig. S5B) $(p<0.01)$. M-mode echocardiography revealed that LVESD and LVEDD in fra- $1^{\text {tg }}$ hearts were significantly increased $(p \mathrm{lt} ; 0.01)$ (Fig. 3C,D). Moreover, mortality was increased in $\mathrm{rra}^{-1^{\text {tg }}}$ mice after aortic banding since three out of eight mice died during follow-up. Fra- ${ }^{\text {tg }}$ mice were next subjected to isoproterenol stimulation. The hypertrophic response after infusions of isoproterenol was similar in both fra-1 transgenic and wild-type hearts. However, increased mortality associated with 
Ricci et al.

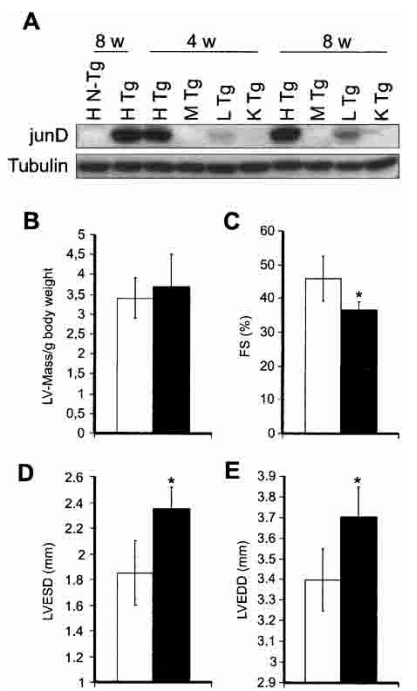

Figure 2. Ventricular dilation and decreased contractility in $\alpha$-MHC-jun $D^{\mathrm{tg}}$ mice. (A) Western blotting of total protein extracts from different organs from $\alpha-\mathrm{MHC}-j u n D^{\mathrm{tg}}$ and nontransgenic mice with indicated age using a junD-specific antibody against endogenous and exogenous protein. A strong expression of junD was found in transgenic hearts $(\mathrm{H} \mathrm{Tg})$ compared with nontransgenic hearts $(\mathrm{H} \mathrm{N}-\mathrm{Tg})$, transgenic skeletal muscles $(\mathrm{M} \mathrm{Tg})$, transgenic livers $(\mathrm{L} \mathrm{Tg})$, and transgenic kidneys $(\mathrm{K} \mathrm{Tg})$. Tubulin was used as a loading control. $(B)$ Left ventricular (LV) mass/gram body weight assessed by echocardiography in $\alpha-M H C-j u n D^{\text {tg }}$ mice (black bars) was only slightly but not significantly increased compared with wild-type mice (open bars). (C) Fractional shortening (FS) in $\alpha$-MHCjun $D^{\text {tg }}$ mice (black bars) was significantly decreased compared with wild-type mice (open bars) and was associated with increased left ventricular end systolic diameters $(D)$ (LVESD) and increased left ventricular end diastolic diameters (LVEDD) $(E)(n=5$, five males, 2 mo old for both genotypes). $\left({ }^{\star}\right) p<0.01$ compared with control group (student unpaired $t$-test).

cardiac decompensation could be observed (data not shown).

\section{Fra- $1^{\text {tg }}$ junD ${ }^{-/-}$mice develop dilative cardiomyopathy}

We next asked whether junD-dependent compensatory cardiac hypertrophy might protect $f r a-1^{\text {tg }}$ mice from heart failure. To answer this question we generated fra-1 transgenic mice, which simultaneously lack junD (fra$1^{\text {tg }}$ jun $D^{-/-}$mice). Mice with all possible genotypes were recovered at Mendelian frequency. Approximately $60 \%$ of $f r a-1^{\text {tg }}$ junD $D^{-/-}$mice died within the first 2 wk after birth (Fig. 4A). At necropsy, fra- $1^{\text {tg }}$ junD ${ }^{-/-}$pups displayed enlarged hearts (Fig. 3B). Histological examination showed marked dilation of all cardiac chambers of fra- $1^{\text {tg }}$ jun $D^{-/-}$mice (Supplementary Fig. S6A). No developmental cardiac abnormalities and no defects in other organs could be detected. Dilation of the heart in $\mathrm{rra}^{-1^{\mathrm{tg}}}$ jun $D^{-/-}$mice could not be found immediately before birth (data not shown). Thus, the observed phenotype reflects a rapid progressive process starting after birth together with the switch from the low-pressure fetal to a high-pressure post-natal circulation.

Fra- $1^{\text {tg }}$ jun $D^{-/-}$mice surviving the first month after birth developed peripheral edema and ascites, became dyspneic and lethargic, and died (Fig. 4C). Histopathological analyses revealed signs of advanced chronic hepatic and pulmonary congestion (data not shown). The heart size of adult fra-1 ${ }^{\text {tg }} j u n D^{-/-}$mice was markedly increased (Fig. 4D), which was confirmed by the increased heart-to-body weight ratios in fra- $1^{\text {tg }}$ jun $D^{-/-}$ mice compared with mice with all other genotypes $(p<0.01)$ (Supplementary Fig. S6B). Histological analyses showed cardiomyocyte hypertrophy and disarray (Supplementary Fig. S6C,D). In addition, we found extensive focal interstitial fibrosis in $\mathrm{fra}-1^{\text {tg }} \mathrm{junD}^{-/-}$ventricles (Supplementary Fig. S6E). Overall, the cardiac phenotype in adult fra- $1^{\text {tg }}$ jun $D^{-/-}$mice mimics human heart failure resulting from dilated cardiomyopathy (Hunter and Chien 1999).

\section{Subcellular and molecular analyses of heart phenotype in ra $^{-1} 1^{\text {tg }}$ junD $D^{-/-}$mice}

We next investigated whether overexpression of fra-1 and the lack of junD in the heart affected transcriptional expression of other AP-1 members using RPA. In the fra- $1^{\text {tg }}$ jun $D^{-/-}$hearts the fra-1 transgene was efficiently expressed and junD expression was completely absent. No change in mRNA levels of any other AP-1 members was detected in fra- $1^{\text {tg }}$ jun $D^{-/-}$hearts (Supplementary Fig. S7A). Reactivation of embryonic genes as well as up-regulation of natriuretic peptides and contractile proteins characterize many forms of cardiac hypertrophy (Chien et al. 1993). Indeed, mRNA levels of $\beta$-myosin heavy chain were markedly elevated in $f r a-1^{\mathrm{tg}}$ jun $D^{-/}$ hearts (Fig. 4E). ANF was consistently increased (Fig. 4E). Likewise, $\alpha$-skeletal actin was elevated. Expression of SERCA2a, a Ca ${ }^{2+}$-ATPase of the sarcoplasmic reticulum representing an important regulator of cardiac contraction and relaxation, is often reduced in failing hearts (Muller et al. 2003). In $\mathrm{fra}^{-1^{\mathrm{tg}}} \mathrm{junD}^{-/-}$hearts SERCA2a was slightly down-regulated (Fig. 4E).
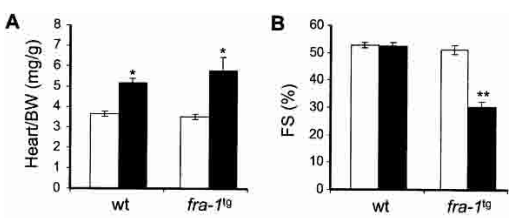

C
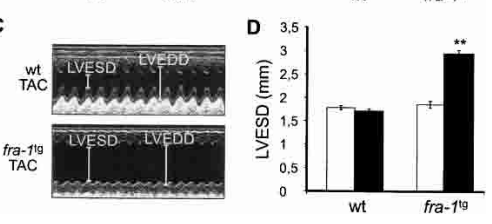

Figure 3. Premature heart failure in fra- $1^{\text {tg }}$ mice upon TAC. $(A)$ Heart-to-body weight (Heart/BW) ratios in $\mathrm{fra}-1^{\text {tg }}$ and wild-type (wt) control mice $6 \mathrm{wk}$ after mild banding (black bars) and sham operation (open bars). No differences in both genotypes could be observed. $(B)$ Fractional shortening (FS) in fra- $1^{\text {tg }}$ mice and wild-type (wt) mice 6 wk after mild TAC (black bars) and sham operation (open bars). Fra $-1^{\text {tg }}$ mice showed decreased contractility after mild TAC. $(C)$ Representative M-mode image of wild-type (wt) and fra- $1^{\text {tg }}$ mice showed increased left ventricular end systolic diameter (LVESD) and left ventricular end diastolic diameters (LVEDD) compared with wild-type (wt) controls, indicating eccentric hypertrophy. (D) Quantification of different measurements of LVESD showed an increase of this parameter in $f r a-1^{\text {tg }}$ mice after mild TAC, indicating ventricular dilation $(n=5$, three males and two females, 3 mo old for TAC and $n=5$, three males and two females, 3 mo old for sham operation for both genotypes). $\left({ }^{\star}\right) p<0.01$ compared with respective sham group (student unpaired $t$-test); $\left(^{\star \star}\right) p<0.01$ compared with all other groups (ANOVA with post hoc student Neuman Keuls multiple comparison test). 
A
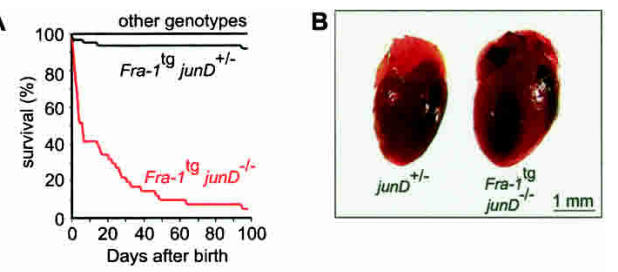

C

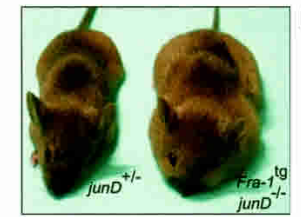

$\mathbf{E}$

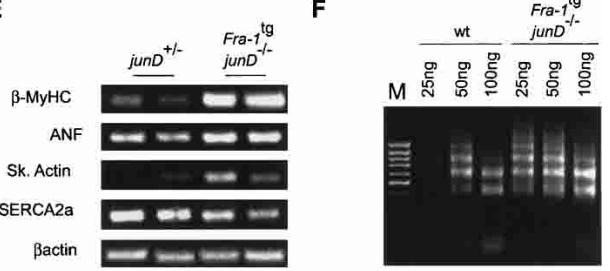

G

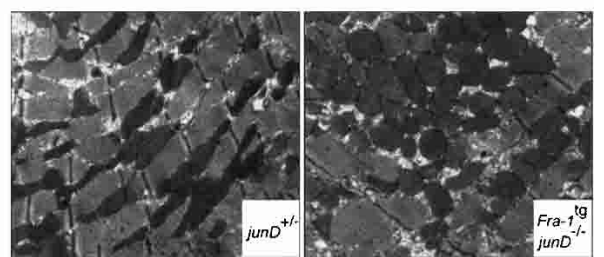

Figure 4. Early post-natal mortality and dilative cardiomyopathy in $f r a-1^{\text {tg }}$ jun $D^{-/-}$mice. (A) Survival curve of offspring from intercrosses of males $\left(f r a-1^{\text {tg }}\right.$ jun $\left.D^{+/-}\right)$and females $\left(j u n D^{-/-}\right.$or jun $D^{+/-}$. Within $3 \mathrm{mo}>90 \%$ of $\mathrm{ra}-1^{\mathrm{tg}} j \mathrm{unD}^{-/-}$mice died suddenly or developed a congestive heart failure. Numbers of mice of each genotype were as follows: fra- $1^{\text {tg }}$ jun $D^{-/-}(n=41$, red $)$; fra- $1^{\text {tg }}$ jun $D^{+/-}(n=62$, black); all other genotypes, fra- $1^{\text {tg }}$, jun $D^{-1-}$, jun $D^{+/-}$, and wild type (wt) ( $n=181$, black). (B) Macroscopical view $(8 \times$ magnification) of fra- $1^{\text {tg }}$ jun $D^{-/-}$and jun $D^{+/-}$control hearts from 3-d-old pups, which showed increased heart size. (C) Surviving fra- ${ }^{\text {tg }}$ jun $D^{-/-}$mice displayed severe edema as compared with jun $D^{+/-}$control mice. $(D)$ Macroscopical view (paraformaldehyde fixed hearts, $2.5 \times$ magnification) of hearts of 6-wk-old fra- $1^{\text {tg }}$ jun $D^{-/-}$mice that showed signs of congestive heart failure and corresponding jun $D^{+/-}$control heart. The sizes of $f r a-1^{\text {tg }}$ jun $D^{-/-}$hearts were markedly increased. $(E)$ Semiquantitative RT-PCR of cardiac hypertrophy markers. $\beta-\mathrm{MyHC}$ was found to be markedly up-regulated in $\mathrm{fra}-1^{\mathrm{tg}}$ jun $\mathrm{D}^{-1-}$ newborn hearts, confirming a myocardial hypertrophic change. $\beta$-Actin was used as a loading control. (ANF) Atrial natriuretic factor; $(\beta-\mathrm{MyHC}) \beta$-myosin heavy chain; (Sk.Actin) $\alpha$-skeletal actin (SERCA2a) $\mathrm{Ca}^{2+}$-ATPase of the sarcoplasmic reticulum. $(F)$ LMPCR-based amplification of DNA laddering with DNA with indicated concentrations from wild-type (wt) control and $\mathrm{fra}-1^{\mathrm{tg}}$ jun $\mathrm{D}^{-1}$ hearts. Increased DNA laddering was observed in $\mathrm{fra}-1^{\mathrm{tg}} j \mathrm{un} \mathrm{D}^{-/-}$ hearts, suggesting increased apoptosis. $(G)$ Electron microscopy of newborn fra- $1^{\text {tg }}$ jun $D^{-/-}$and corresponding jun $D^{+/-}$control hearts. Random distribution of mitochondria and focal myofibrillar disarray in $\mathrm{fra}-1^{\mathrm{tg}}$ jun $\mathrm{D}^{-/-}$cardiomyocytes could be found.

Many forms of cardiomyopathies show cytoskeletal and extracellular matrix defects in cardiomyoctes (Chien 2000). Immunofluorescence (IF) analysis of neonatal hearts with antibodies against $\alpha 2$-laminin and sarcomeric $\alpha$-actinin as well as desmin, vimentin, muscle LIM protein (MLP), $\beta$-dystroglycan, and $\alpha$-sarcoglycan, revealed no differences between control and fra- $1^{\text {tg }}$ junD $D^{-/-}$hearts (Supplementary Fig. S7B; data not shown).

Dilation of hearts was shown to be associated with cardiomyocyte apoptosis (Wencker et al. 2003). Since very few apoptotic cells in control and fra- $1^{\text {tg }}$ junD ${ }^{-/-}$ hearts could be observed by TUNEL (data not shown), we performed a more sensitive ligation-mediated PCR (LMPCR) DNA fragmentation assay. Indeed, DNA fragmentation was increased in fra- $1^{\text {tg }}$ jun $D^{-/-}$hearts (Fig. 4F). Although a chronic low rate cardiomyocyte death may lead to ventricular dilation and dilative cardiomyopathy, these results do not prove whether apoptosis is causally involved in the observed heart phenotype. Many key events in the apoptotic machinery are linked to mitochondria (Green and Reed 1998). Therefore, we next analyzed whether the cardiomyopathy in fra- ${ }^{\text {tg }}$ jun $D^{-/}$ mice could be associated with a primary mitochondrial defect, which leads to mitochondrial-associated cell death. Transmission electron microscopy revealed that mitochondria were randomly dispersed in clusters and appeared swollen in $\mathrm{fra}_{-} 1^{\mathrm{tg}}$ jun $\mathrm{D}^{-1-}$ cardiomyocytes (Fig. 4G). To assess the mitochondrial content, the relative level of mitochondrial DNA was examined by Southern blot analysis of cytochrome b, a mitochondrial-encoded gene, as previously described (Naya et al. 2002). The mitochondrial DNA copy number was equal in wild-type and rra $^{-1^{\text {tg }}}$ jun $\mathrm{D}^{-/-}$hearts, suggesting that the total cellular mitochondrial content in fra- $1^{\text {tg }}$ jun $D^{-/-}$mice is not increased (Supplementary Fig. S8A). To address whether there is a primary mitochondrial defect in these mice, we investigated mitochondrial function in mouse embryonic fibroblasts (MEFs). Mitochondrial transmembrane potential $\left(\Delta \Psi_{\mathrm{m}}\right)$ was monitored by tetramethylrhodamine methyl ester (TMRM), a fluorescent probe that accumulates in polarized mitochondria and is released when $\Delta \Psi_{\mathrm{m}}$ decreases. Addition of oligomycin to fra- $1^{\mathrm{tg}}$ jun $D^{-/-}$MEFs resulted in fast mitochondrial depolarization, whereas in controls $\Delta \Psi_{\mathrm{m}}$ was unchanged (Supplementary Fig. S8B). A markedly increased basal polarization of mitochondria could be observed in $\mathrm{ra}^{-1^{\text {tg }}}$ junD ${ }^{-/-}$ cells, since fluorescence emission was increased about three times at the start of the measurements /data not shown). Defects in mitochondrial polarization have been associated with increased apoptosis (Irwin et al. 2003). Moreover, primary changes in mitochondrial function are reported to severely affect cardiac function whereby only minor defects in other organs can be detected (Wallace 2000).

Recent studies in mice and humans provide evidence that specific forms of cardiac hypertrophy triggered by specific pathways seem to be associated with cardiac dilation and heart failure and do not represent a normal adaptive growth response (Levy et al. 1990; Wettschureck et al. 2001; Barki-Harrington and Rockman 2003).

Although dispensable in cardiac hypertrophy, overexpression of fra-1 resulted in an overshooting response upon mechanical pressure overload, leading to premature heart failure. The data in junD ${ }^{-/-}$mice after transaortic constriction suggest that junD is required for adaptive concentric hypertrophy in heart and therefore might be protective against transition from concentric/ compensated to eccentric/decompensated hypertrophy. We also show that these protective effects prevented spontaneous heart failure in $\mathrm{fra}-1^{\mathrm{tg}}$ mice since $\mathrm{fra}-1^{\mathrm{tg}}$ jun $D^{-/-}$mice developed a dilative cardiomyopathy. Moreover, we provide evidence that a primary mitochondrial dysfunction might contribute to the observed cardiac phenotype in ra $^{-1^{\mathrm{tg}}}$ jun $D^{-/-}$mice. 
On the other hand, we show that ectopic expression of junD specifically in heart leads to a spontaneous heart dilation, and cardiomyocytes overexpressing junD exhibit pronounced hypertrophy. These experiments indicate that junD also seems to promote maladaptive hypertrophy when expressed at unphysiological levels.

We conclude that a well-balanced expression of junD is crucial for heart integrity as well as function, which is supported by the fact that junD was only slightly induced after TAC, but was expressed at high steady-state levels in hearts without stimulation. Thus, junD and fra-1 might represent potential therapeutic targets in heart failure patients in future.

\section{Materials and methods}

Generation of fra- $1^{\text {tg }}$, junD ${ }^{-/-}$, and fra- $1^{\Delta / \Delta}$ mice

Fra-1 $^{\text {tg }}$ (C57/BL6/129sv) and junD ${ }^{-/-}$deficient mice (C57/BL6/129sv) have been described previously (Jochum et al. 2000; Thepot et al. 2000). These mice have been intercrossed to obtain $\mathrm{fra}-1^{\mathrm{tg}}$ jun $\mathrm{D}^{-/-}$mice. F2 generations have been used for all experiments. Fra-1 conditional knockout mice (C57/BL6/129ola) have been generated by crossing fra-1 floxed mice with the MORE-Cre mice (Eferl et al. 2004).

Generation of $\alpha-M H C-\mathrm{unD}^{\text {tg }}$ mice

The $\alpha$-MHC-junD transgene construct consists of the entire junD cDNA cloned into the Sall-digested pMHC, poly A vector (kind gift of Dr. J. Robbins, Division of Molecular Cardiovascular Biology, Department of Pediatrics, The Cincinnati Children's Hospital Medical Center, Cincinnati, $\mathrm{OH})$. The construct was injected into the male pronucleus of fertilized single-cell embryos to produce $\alpha-M H C-j u n D^{\text {tg }}$ mice. Transgenic founders were identified by Southern blot analysis of tail DNA according to standard procedures. Only offspring from founder mouse number 9 were used for analyses.

Transthoracic echocardiography

Echocardiography was performed as previously described (Crackower et al. 2002).

Transaortic banding

Transverse aortic banding or sham operation was performed in age- and weight-matched mice as previously described (Tarnavski et al. 2004).

\section{Administration of isoproterenol}

Isoproterenol was administered chronically to mice using a surgically implanted mini-osmotic pump (ALZET) that released isoproterenol in $0.9 \% \mathrm{NaCl}$ at a rate of $30 \mathrm{mg} / \mathrm{kg} / \mathrm{d}$. Control mice carried pumps containing $0.9 \% \mathrm{NaCl}$ solution alone.

\section{Transfection experiments}

Neonatal rat hearts were dissected, digested with collagenase (Worthington Biochemical) as well as pancreatin (GIBCO Laboratories), and plated as previously described (Auerbach et al. 1997). Two hours prior to transfection, plating medium was exchanged to transfection medium $120 \%$ M199, 73\% DBSS-K [6.8 g/L NaCl, 0.14 mM NaH${ }_{2} \mathrm{PO}_{4}, 0.2 \mathrm{mM} \mathrm{CaCl}_{2}$, $0.2 \mathrm{mM} \mathrm{MgSO}_{4}, 1 \mathrm{mM}$ dextrose, $\left.2.7 \mathrm{mM} \mathrm{NaHCO}_{3}\right], 4 \%$ horse serum, and $2 \%$ glutamine $200 \mathrm{mM}$ ). Cells have been transfected with a plasmid containing Flag-tagged junD cDNA (generous gift from Dr. Latifa Bakiri) under the control of the cytomegalovirus promoter using Escort III (Sigma) according to the manufacturer's protocol. After $4 \mathrm{~h}$, medium has been replaced by maintenance medium (Auerbach et al. 1997). After 72 h, cells have been fixed, costained with a mouse monoclonal anti-Flag antibody (Chemicon) and phalloidin (Molecular Probes), mounted, and analyzed by fluorescence microscopy as previously described. Cell size has been measured using ImageJ image processing software. Experiments have been performed twice.

Histology, IF, and electron microscopy (EM)

For histology, hearts were fixed with $4 \%$ buffered formalin and embedded in paraffin. Interstitial fibrosis was analyzed by using the Elastin van Gieson staining. IF was performed on nonfixed cryosections $(5 \mu \mathrm{m})$ and stainings were performed according to manufacturer's recommendations. IF antibodies including $\alpha$-actinin (sarcomeric) and $\alpha 2$-laminin were purchased from Sigma. EM was performed with hearts fixed in $2.5 \%$ glutaraldehyde diluted in phosphate buffer $(0.1 \mathrm{M}$ at $\mathrm{pH} 7.4)$ according to standard procedures. Myocyte cross-sectional area was determined by tracing the outlines of cardiomyocytes in trichrome-stained sections from the left ventricular region using a video imaging program (Northern Eclipse 5.0) as previously described (Oudit et al. 2003).

\section{$R P A$}

Newborn mice were sacrificed and total RNA was isolated with the TRIZOL protocol (SIGMA). Ten micrograms was used for each RPA reaction. RPA was performed using the RiboQuant multi-probe RPA system mJun/Fos and mAPO-2 according to the manufacturer's protocol.

\section{Semiquantitative and real-time RT-PCR}

cDNA out of total ventricular RNA was synthesized by using the ReadyTo-Go You-Prime First-Strand beats (Amersham Biosciences). Semiquantitative PCR was performed with three different dilutions of cDNA and repeated three times. RNA expression levels for ANF and BNP after banding experiments in the left ventricle was quantified with Real-Time TaqMan RT-PCR using ABI Prism 7700 sequence detection system. Briefly, $1 \mu \mathrm{g}$ of total RNA was reverse transcribed using random hexamers. Taqman reactions were carried out in 96 well plates using $0.5 \%$ cDNA, $12.5 \mu \mathrm{L}$ of $2 \times$ Taqman universal PCR mastermix, $100 \mu \mathrm{M}$ probe, and $200 \mu \mathrm{M}$ of each primer and water to a final volume of $25 \mu \mathrm{L}$. $18 \mathrm{~S}$ rRNA was used as an endogenous control and every sample was analyzed in duplicate.

\section{Blunt-end $L M-P C R$}

Genomic DNA was isolated from wild-type and fra-1 ${ }^{\mathrm{tg}}$ jun $D^{-/-}$hearts and analyzed by LM-PCR as previously described (Blaschke et al. 1996).

\section{Assessment of mitochondrial content by Southern blotting} Southern blotting was performed according to standard procedures and as previously described (Naya et al. 2002).

\section{Mitochondrial membrane potential assay}

MEFs with different genotypes were plated onto glass coverslips and cultured in DMEM containing 10\% FCS $24 \mathrm{~h}$ before starting the experiment. We employed the fluorescence dye TMRM (Sigma) to monitor the $\Delta \Psi_{\mathrm{m}}$ as described (Irwin et al. 2003). Briefly, fibroblasts were loaded with TMRM for $20 \mathrm{~min}$ at $37^{\circ} \mathrm{C}$. Cells were then placed on the stage of Olympus MT20 inverted fluorescence microscope and Oligomycin (Sigma, 5 $\mu \mathrm{M}$ final concentration) was added. Temperature was maintained at $37^{\circ} \mathrm{C}$. Emission was monitored at $580 \mathrm{~nm}$. Sequential images were collected in 60-s intervals for $40 \mathrm{~min}$. The time course of $\Delta \Psi_{\mathrm{m}}$ (measured as arbitrary fluorescence units) was performed using Olympus CellR software.

\section{Statistical analysis}

Data are presented as mean \pm SEM. Statistical significance of differences was calculated using an ANOVA with post hoc student Neuman Keuls multiple comparison test and student unpaired $t$-test, respectively. Significance was accepted at the level of $p<0.05$.

\section{Acknowledgments}

We are grateful to Evelyne Perriard who performed transfection experiments; Andreas Bichl for maintaining the mouse house; Pico Caroni for providing us the MLP antibody; L.B., Maria Sibilia, and Christian Matter for critical reading; and Hannes Tkadletz for help with preparing the illustrations. The IMP is funded by Boehringer Ingelheim and R.R. was supported by an European Union Fellowship program (Marie Curie Individual Fellowship) and "Forschungskredit 2003" from University of Zurich. A.A. and D.K. have been supported by the Swiss National Science Foundation (grant no. 3100-066976).

\section{References}

Andreucci, J.J., Grant, D., Cox, D.M., Tomc, L.K., Prywes, R., Goldhamer, D.J., Rodrigues, N., Bedard, P.A., and McDermott, J.C. 2002. Composition and function of AP-1 transcription complexes during muscle cell differentiation. J. Biol. Chem. 277: 16426-16432. 
Auerbach, D., Rothen-Ruthishauser, B., Bantle, S., Leu, M., Ehler, E., Helfman, D., and Perriard, J.C. 1997. Molecular mechanisms of myofibril assembly in heart. Cell Struct. Funct. 22: 139-146.

Barki-Harrington, L. and Rockman, H.A. 2003. Sensing heart stress. Nat. Med. 9: 19-20.

Blaschke, A.J., Staley, K., and Chun, J. 1996. Widespread programmed cell death in proliferative and postmitotic regions of the fetal cerebral cortex. Development 122: 1165-1174.

Brancaccio, M., Fratta, L., Notte, A., Hirsch, E., Poulet, R., Guazzone, S., De Acetis, M., Vecchione, C., Marino, G., Altruda, F., et al. 2003. Melusin, a muscle-specific integrin $\beta 1$-interacting protein, is required to prevent cardiac failure in response to chronic pressure overload. Nat. Med. 9: 68-75.

Chien, K.R. 1999. Stress pathways and heart failure. Cell 98: 555-558.

2000. Genomic circuits and the integrative biology of cardiac diseases. Nature 407: 227-232.

Chien, K.R., Zhu, H., Knowlton, K.U., Miller-Hance, W., van-Bilsen, M., O'Brien, T.X., and Evans, S.M. 1993. Transcriptional regulation during cardiac growth and development. Annu. Rev. Physiol. 55: 77-95.

Crackower, M.A., Oudit, G.Y., Kozieradzki, I., Sarao, R., Sun, H., Sasaki, T., Hirsch, E., Suzuki, A., Shioi, T., Irie-Sasaki, J., et al. 2002. Regulation of myocardial contractility and cell size by distinct PI3KPTEN signaling pathways. Cell 110: 737-749.

Eferl, R., Hoebertz, A., Schilling, A.F., Rath, M., Karreth, F., Kenner, L., Amling, M., and Wagner, E.F. 2004. The Fos-related antigen Fra-1 is an activator of bone matrix formation. EMBO J. 23: 2789-2799.

Frey, N. and Olson, E.N. 2003. Cardiac hypertrophy: The good, the bad, and the ugly. Annu. Rev. Physiol. 65: 45-79.

Green, D.R. and Reed, J.C. 1998. Mitochondria and apoptosis. Science 281: 1309-1312.

Hunter, J.J. and Chien, K.R. 1999. Signaling pathways for cardiac hypertrophy and failure. N. Engl. J. Med. 341: 1276-1283.

Irwin, W.A., Bergamin, N., Sabatelli, P., Reggiani, C., Megighian, A., Merlini, L., Braghetta, P., Columbaro, M., Volpin, D., Bressan, G.M., et al. 2003. Mitochondrial dysfunction and apoptosis in myopathic mice with collagen VI deficiency. Nat. Genet. 35: 367-371.

Jochum, W., David, J.P., Elliott, C., Wutz, A., Plenk Jr., H., Matsuo, K., and Wagner, E.F. 2000. Increased bone formation and osteosclerosis in mice overexpressing the transcription factor Fra-1. Nat. Med. 6: 980-984.

Jochum, W., Passegue, E., and Wagner, E.F. 2001. AP-1 in mouse development and tumorigenesis. Oncogene 20: 2401-2412.

Kovacic-Milivojevic, B. and Gardner, D.G. 1995. Fra-1, a Fos gene family member that activates atrial natriuretic peptide gene transcription. Hypertension 25: 679-682.

Levy, D., Garrison, R.J., Savage, D.D., Kannel, W.B., and Castelli, W.P. 1990. Prognostic implications of echocardiographically determined left ventricular mass in the Framingham Heart Study. N. Engl. J. Med. 322: 1561-1566.

Muller, F.U., Lewin, G., Matus, M., Neumann, J., Riemann, B., Wistuba, J., Schutz, G., and Schmitz, W. 2003. Impaired cardiac contraction and relaxation and decreased expression of sarcoplasmic $\mathrm{Ca}^{2+}$. ATPase in mice lacking the CREM gene. FASEB J. 17: 103-105.

Naya, F.J., Black, B.L., Wu, H., Bassel-Duby, R., Richardson, J.A., Hill, J.A., and Olson, E.N. 2002. Mitochondrial deficiency and cardiac sudden death in mice lacking the MEF2A transcription factor. Nat. Med. 8: 1303-1309.

Olson, E.N. and Schneider, M.D. 2003. Sizing up the heart: Development redux in disease. Genes \& Dev. 17: 1937-1956.

Oudit, G.Y., Crackower, M.A., Eriksson, U., Sarao, R., Kozieradzki, I., Sasaki, T., Irie-Sasaki, J., Gidrewicz, D., Rybin, V.O., Wada, T., et al. 2003. Phosphoinositide 3-kinase $\gamma$-deficient mice are protected from isoproterenol-induced heart failure. Circulation 108: 2147-2152.

Parker, T.G. and Schneider, M.D. 1991. Growth factors, proto-oncogenes, and plasticity of the cardiac phenotype. Annu. Rev. Physiol. 53: 179200.

Pollack, P.S., Pasquarello, L.M., Budjak, R., Fernandez, E., Soprano, K.J., Redfern, B.G., and Goldman, B. 1997. Differential expression of c-jun and junD in end-stage human cardiomyopathy. J. Cell. Biochem. 65: 245-253.

Rockman, H.A., Ross, R.S., Harris, A.N., Knowlton, K.U., Steinhelper, M.E., Field, L.J., Ross Jr., J., and Chien, K.R. 1991. Segregation of atrial-specific and inducible expression of an atrial natriuretic factor transgene in an in vivo murine model of cardiac hypertrophy. Proc. Natl. Acad. Sci. 88: 8277-8281.

Tarnavski, O., McMullen, J.R., Schinke, M., Nie, Q., Kong, S., and Izumo, S. 2004. Mouse cardiac surgery: Comprehensive techniques for the generation of mouse models of human diseases and their application for genomic studies. Physiol. Genomics 16: 349-360.

Thepot, D., Weitzman, J.B., Barra, J., Segretain, D., Stinnakre, M.G., Babinet, C., and Yaniv, M. 2000. Targeted disruption of the murine junD gene results in multiple defects in male reproductive function. Development 127: 143-153.

van Wamel, J.E., Ruwhof, C., van der Valk-Kokshoorn, E.J., Schrier, P.I., and van der Laarse, A. 2000. Rapid gene transcription induced by stretch in cardiac myocytes and fibroblasts and their paracrine influence on stationary myocytes and fibroblasts. Pflugers Arch. 439: 781788.

Wallace, D.C. 1999. Mitochondrial diseases in man and mouse. Science 283: $1482-1488$.

. 2000. Mitochondrial defects in cardiomyopathy and neuromuscular disease. Am. Heart J. 139: S70-S85.

Wencker, D., Chandra, M., Nguyen, K., Miao, W., Garantziotis, S., Factor, S.M., Shirani, J., Armstrong, R.C., and Kitsis, R.N. 2003. A mechanistic role for cardiac myocyte apoptosis in heart failure. $J$. Clin. Invest. 111: 1497-1504.

Wettschureck, N., Rutten, H., Zywietz, A., Gehring, D., Wilkie, T.M., Chen, J., Chien, K.R., and Offermanns, S. 2001. Absence of pressure overload induced myocardial hypertrophy after conditional inactivation of G $\alpha \mathrm{q} / \mathrm{G} \alpha 11$ in cardiomyocytes. Nat. Med. 7: 1236-1240. 


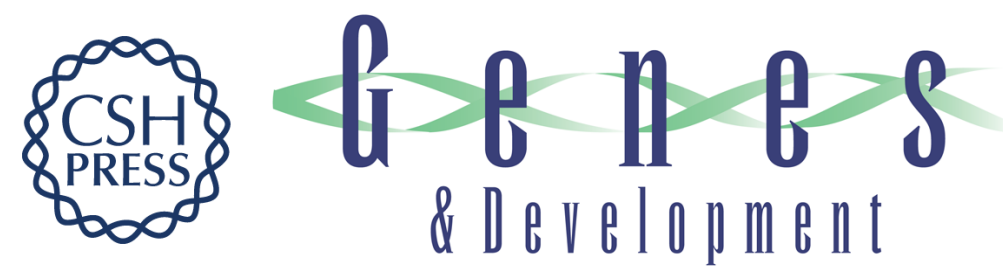

\section{Distinct functions of junD in cardiac hypertrophy and heart failure}

Romeo Ricci, Urs Eriksson, Gavin Y. Oudit, et al.

Genes Dev. 2005, 19:

Access the most recent version at doi:10.1101/gad.327005

Supplemental
Material http://genesdev.cshlp.org/content/suppl/2004/12/29/19.2.208.DC1

References This article cites 32 articles, 10 of which can be accessed free at: http://genesdev.cshlp.org/content/19/2/208.full.html\#ref-list-1

License

Email Alerting Receive free email alerts when new articles cite this article - sign up in the box at the top Service right corner of the article or click here.

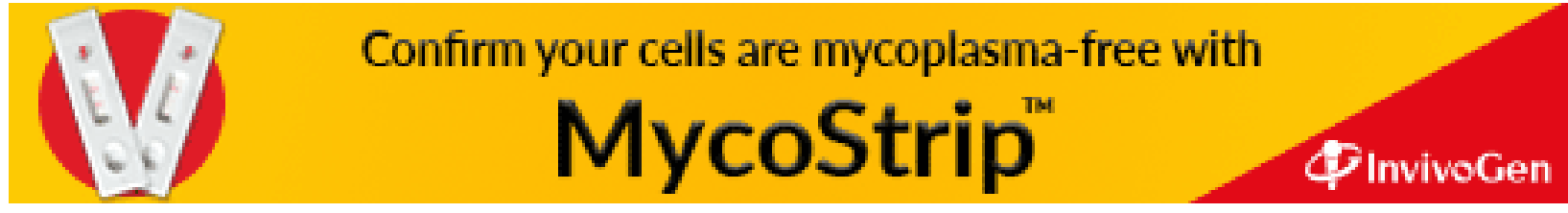

